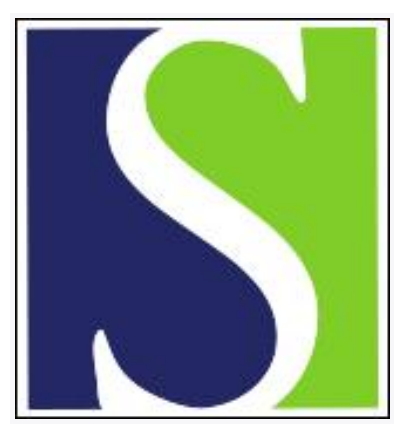

Scand J Work Environ Health 1996;22(5):369-374

https://doi.org/10.5271/sjweh.156

Issue date: Oct 1996

\title{
Hemorheology in occupational lead exposure
}

by Osterode W

Key terms: blood viscosity; delta-aminolevulinic acid dehydrase; erythrocyte; lead

This article in PubMed: www.ncbi.nlm.nih.gov/pubmed/8923611

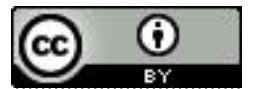




\title{
Hemorheology in occupational lead exposure
}

\author{
by Wolf Osterode, $M D^{1}$
}

Osterode W. Hemorheology in occupational lead exposure. Scand J Work Environ Health 1996;22:369—73.

Objectives The purpose of this investigation was to study hemorheological parameters in occupationally lead exposed men.

Material and methods For 15 clinically healthy lead-exposed male subjects [age 34.6 (SD 8) years] the viscous $\left(\varepsilon^{\prime}\right)$ and elastic $\left(\varepsilon^{\prime \prime}\right)$ components of whole blood viscosity corrected for $45 \%$ hematocrit were measured for shear rates between $1 \cdot \mathrm{s}^{-1}-100 \cdot \mathrm{s}^{-1}$ at $37^{\circ} \mathrm{C}$. Moreover, lead concentrations in blood and urine and the deltaaminolevulinic acid dehydrase level were determined. Fifteen unexposed age-matched men were used as referents.

Results The mean lead concentration in the blood and urine of the lead-exposed men was 48.7 (SD 16.2) $\mu \mathrm{g}$. $\mathrm{dl}^{-1}$ and 38.8 (SD 17.1) $\mu \mathrm{g} \cdot \mathrm{g}$ creatinine ${ }^{-1}$, respectively. While $\varepsilon^{\prime \prime}$ was significantly increased only at low shear rates, $\varepsilon^{\prime}$ was elevated throughout the investigated shear range in comparison with the values of the unexposed referents. These results are characteristic of erythrocytes with enhanced rigidity. The aggregation and filtration index of erythrocytes were significantly elevated for the lead-exposed workers. A positive correlation existed between lead in blood and $\varepsilon^{\prime}$ or $\varepsilon^{\prime \prime}$, whereas $\delta$-aminolevulinic acid dehydrase and $\varepsilon^{\prime}$ or $\varepsilon^{\prime \prime}$ were inversely correlated. No differences in plasma viscosity or in lipid status could be detected.

Conclusion Increased blood lead concentrations can be considered an additional risk factor for vascular diseases predisposing towards microvascular occlusion.

Key terms blood viscosity, erythrocyte, lead, $\delta$-aminolevulinic acid dehydrase.

Approximately $95 \%$ of the circulating fraction of lead in the human body is bound to erythrocytes (1). Several investigations on erythrocyte membranes in lead exposure have shown modulations in the mechanical properties of the erythrocytes, for example, shortened erythrocyte survival (2-4) and an increase in osmotic resistance $(2,4,5)$. In addition, biochemical studies have documented protein conformational changes and an increase in cholesterol of the inner core of the erythrocyte membranes of lead-exposed subjects $(6,7)$. Moreover an increase in lipid peroxidation in serum and an inhibition of erythrocyte superoxide dismutase activity have been shown $(8-10)$. Thus modulations in erythrocyte rigidity should be expected. Investigations on the fluidity and viscosity of erythrocytes were performed by fluorescence polarization methods (7), electron spin resonance (11), or other techniques. Hemoglobin-depleted ghost membranes were preferably used in these studies. The results were not always unequivocal. Conflicting data resulting in an increase or decrease in erythrocyte membrane fluidity have been found with the distinct methods and their inherent restrictions and limitations in relation to specific structural composition. In the course of ghost mem- brane preparation a disruption of the interaction between membrane lipids and cytoskeletal proteins occurs due to lysis and repeated washing with solutions of low ionic strength, a process which leads to differences in erythrocyte ghost membranes and intact erythrocyte fluidity (12).

It seems questionable how far such results can be extrapolated to whole blood viscosity in lead-exposed subjects. Whole blood viscosity depends predominantly on hematocrit, plasma viscosity $\left(\sigma_{\mathrm{PL}}\right)$, certain plasma proteins, and erythrocyte deformability and varies with shear stress. Because of the lack of these hemorheological data for lead-exposed workers, we investigated whole blood viscosity in lead-exposed and lead-unexposed persons by using dynamic theological measurements at shear rates between $1 \cdot \mathrm{s}^{-1}$ and $100 \cdot \mathrm{s}^{-1}$.

\section{Subjects}

Twenty lead-exposed male subjects working at a battery factory gave their informed consent for collecting an

1 Clinic of Internal Medicine IV, Department of Occupational Medicine, University of Vienna, Austria.

Reprint requests to: DDr Wolf Osterode, Universitätsklinik für Innere Medizin IV, Klinische Abteilung für Arbeitsmedizin, Währinger Gürtel 18-20, A - 1090 Wien, Austria. 
Table 1. Mean subject data and mean laboratory values for the lead-exposed and lead-unexposed group.

\begin{tabular}{|c|c|c|c|c|c|c|c|c|c|c|c|c|c|c|c|c|}
\hline \multirow[t]{3}{*}{ Group } & \multirow{2}{*}{\multicolumn{2}{|c|}{$\begin{array}{l}\text { Blood lead } \\
\left(\left.\mu \mathrm{mol} \cdot\right|^{-1}\right)\end{array}$}} & \multirow{2}{*}{\multicolumn{2}{|c|}{$\begin{array}{l}\text { Urinary lead } \\
\left(\text { umol }\left.^{-1} \cdot\right|^{-1} \cdot g\right. \\
\left.\text { creatinine }^{-1}\right)\end{array}$}} & \multirow{2}{*}{\multicolumn{2}{|c|}{$\begin{array}{c}\text { Delta- } \\
\text { aminolevulinic } \\
\text { acid } \\
\text { dehydrase } \\
\left(\mu \mathrm{mol} \cdot \mathrm{I}^{-1}\right)\end{array}$}} & \multicolumn{6}{|c|}{ Cholesterol } & \multirow{2}{*}{\multicolumn{2}{|c|}{$\begin{array}{l}\text { Triglycerides } \\
\left(\text { umol. }\left.\right|^{-1}\right)\end{array}$}} & \multirow{2}{*}{\multicolumn{2}{|c|}{$\begin{array}{l}\text { Fibrogen } \\
\left(\mu \mathrm{mol} \cdot \mathrm{I}^{-1}\right)\end{array}$}} \\
\hline & & & & & & & \multicolumn{2}{|c|}{$\begin{array}{c}\text { Total } \\
\text { cholesterol } \\
\left(\left.\mu \mathrm{mol} \cdot\right|^{-1}\right)\end{array}$} & \multicolumn{2}{|c|}{$\begin{array}{l}\text { High-density } \\
\text { lipoprotein } \\
\left(\left.\mu m o l \cdot\right|^{-1}\right)\end{array}$} & \multicolumn{2}{|c|}{$\begin{array}{l}\text { Low-density } \\
\text { lipoprotein } \\
\left(\left.\mu \mathrm{mol} \cdot\right|^{-1}\right)\end{array}$} & & & & \\
\hline & Mean & $S D$ & Mean & SD & Mean & SD & Mean & SD & Mean & $\mathrm{SD}$ & Mean & SD & Mean & SD & Mean & $\mathrm{SD}$ \\
\hline $\begin{array}{l}\text { Lead- } \\
\text { exposed }\end{array}$ & 2.35 & 0.78 & 1.87 & 0.83 & 189 & 101 & 5.31 & 1.42 & 1.06 & 0.46 & 3.69 & 1.19 & 1.64 & 0.84 & 7.59 & 1.41 \\
\hline $\begin{array}{l}\text { Lead- } \\
\text { unexposed }\end{array}$ & 0.25 & 0.1 & 0.20 & 0.15 & 401 & 86 & 5.51 & 1.27 & 1.11 & 0.28 & 3.59 & 0.96 & 1.49 & 0.93 & 7.21 & 0.94 \\
\hline
\end{tabular}

additional blood sample for measuring blood viscosity at their regular check-up for lead exposure. Due to the study design only clinically healthy persons were included in this investigation. Data from subjects with abnormal values in the usual blood chemistry work up or participants with known diabetes or cardiovascular, renal, or hepatic diseases were excluded. With these restrictions applied 15 lead-exposed workers with a mean-age of 34.6 (SD 8) years remained. Therefore alterations in blood viscosity caused by other diseases could be excluded. These workers had had an average of 8.4 (SD 3.2 ) years of exposure to lead.

Data from 15 healthy age-matched [mean age 33.5 (SD 7) years] unexposed men, all with nearly the same nicotine consumption $\left(10-20\right.$ cigarettes $\left.\cdot \mathrm{d}^{-1}\right)$ as the lead-exposed workers, were used as the referents.

As compared with the unexposed workers, about a 10-fold elevation in the mean lead concentrations in blood and urine were measured in the lead-exposed subjects (table 1).

\section{Methods}

\section{Viscoelasticity}

Blood is a viscoelastic fluid $(13-15)$. For the study of the elastic and viscous components of whole blood, dynamic rheological measurements are necessary (14). Measurements of whole blood viscosity with, for example, a plate or cone viscosimeter, estimate the apparent viscosity which is defined by $\varepsilon_{\mathrm{A}}=\left(\varepsilon^{12}-\varepsilon^{\prime \prime 2}\right)^{1 / 2}$. Therefore, for both groups the components of whole blood

Table 2. Mean aggregation and filtration index of the erythrocytes of the lead-exposed and lead-unexposed workers.

\begin{tabular}{|c|c|c|c|c|c|c|}
\hline \multirow[t]{2}{*}{ Group } & \multicolumn{3}{|c|}{ Aggregation } & \multicolumn{3}{|c|}{ Filtration index } \\
\hline & Mean & SD & P-value & Mean & SO & P-value \\
\hline $\begin{array}{l}\text { Exposed } \\
\text { Unexposed }\end{array}$ & $\begin{array}{l}1.23 \\
0.89\end{array}$ & $\begin{array}{l}0.12 \\
0.25\end{array}$ & 0.001 & $\begin{array}{l}1.31 \\
1.02\end{array}$ & $\begin{array}{l}0.23 \\
0.14\end{array}$ & 0.003 \\
\hline
\end{tabular}

viscosity were measured in blood anticoagulated with EDTA (ethylenediaminetetraacetic acid) using a capillary viscosimeter (Anto Paar CoKG, Graz, Austria) at a constant oscillation frequency of $2 \mathrm{~Hz}$ for shear rates between $1 \cdot \mathrm{s}^{-1}$ to $100 \cdot \mathrm{s}^{-1}$. Blood samples were kept rotating until the estimation of whole blood viscosity to avoid sedimentation. The measurements were performed within $1 \mathrm{~h}$ after the blood collection at a constant temperature of $37 \pm 0.1^{\circ} \mathrm{C}$. The blood samples were adjusted to a hematocrit of $45 \% \pm 1 \%$.

As the viscoelasticity of whole blood is a nonlinear function of shear stress ( $\tau$ ), Chmiel et al (14) defined the following two equations characterizing an aggregation (AI) and flexibility (FI) index for erythrocytes:

$$
\begin{aligned}
& \mathrm{AI}=\left[\varepsilon_{(\tau=1)}^{\prime \prime}-\varepsilon_{(\tau=20)}^{\prime \prime}\right]_{L E, ~ N E} /\left[\varepsilon_{(\tau=1)}^{\prime \prime}-\varepsilon_{(\tau=20)}^{\prime \prime}\right]_{\mathrm{C}} \\
& {\left[\left(\sigma_{\mathrm{FI}}\right) \mathrm{C} /\left(\sigma_{\mathrm{PI}}\right)_{\mathrm{LE}, \mathrm{NE}}\right]} \\
& \mathrm{FI}=\left[\varepsilon_{(\tau=20)}^{\prime}-\varepsilon_{(\tau=100)}^{\prime}\right]_{\mathrm{LE}, \mathrm{NE}} /\left[\varepsilon_{(\tau=20)}^{\prime}-\varepsilon_{(\tau=1003}^{\prime}\right]_{\mathrm{C}} \\
& {\left[\left(\sigma_{\mathrm{PI}}\right)_{\mathrm{C}} /\left(\sigma_{\mathrm{PI}}\right)_{\mathrm{LE}, \mathrm{NE}}\right] \quad \text { (equation 1) }}
\end{aligned}
$$

in which $\tau$ is the shear stress $\left[1 \cdot \mathrm{s}^{-1}, 20 \cdot \mathrm{s}^{-1}\right.$ and 100 . $\mathrm{s}^{-1}$, and $\mathrm{C}$ denotes values of a healthy reference group $(\mathrm{N}=25)$, which had been determined before.

Equations 1 and 2 were used for calculating the aggregation and flexibility (table 2).

\section{Lead concentrations in blood and urine}

The lead concentrations in blood (B-Pb) and urine (U-Pb) were measured by atomic absorption using a Perkin Elmer 2380 spectrophotometer with a graphite furnace. Delta-aminolevulinic acid dehydrase (ALA-D) in blood was determined as described previously $(16,17)$.

Plasma and blood chemistry were routinely determined by standard methods.

\section{Statistical analysis}

For the statistical analysis of the data, the t-test, the Bonferroni-Holm test, and the Spearman regression $\left(\mathrm{r}_{\mathrm{S}}\right)$ were used. 


\section{Results}

\section{Viscoelasticity}

After hematocrit adjustment to $45 \%$, the mean elastic component of whole blood was significantly elevated at lower shear rates for the exposed workers. At shear rates of $>10 \cdot \mathrm{s}^{-1}$ no significant difference between the exposed and unexposed workers could be observed in the Bonferroni test. A maximum deviation of about $20 \%$ existed at a shear rate of $1 \cdot \mathrm{s}^{-1}$. The mean viscous component of whole blood was significantly higher for the exposed workers at all the shear rates. The mean deviations varied between $9 \%$ and $10 \%$ (figure 1 ). No difference existed in the mean plasma viscosity $\left(\varepsilon_{\mathrm{PL}}\right)$ between the unexposed and exposed workers [1.28 (SD 0.03) and 1.30 (SD 0.04) mPas, respectively].

\section{Dose-response considerations}

Significant correlations between the B-Pb and $\varepsilon^{\prime}$ or $\varepsilon^{\prime \prime}$ were calculated for the exposed group (table 3 ), while there was only a weak correlation between U-Pb corrected for the individual creatinine values at low shear rates and $\varepsilon^{\prime \prime}\left(\mathrm{r}_{\mathrm{S}}=0.66, \mathrm{P}=0.039\right)$. When all the values of the exposed and unexposed workers were included in the calculations, there was only a slight increase in $r_{S}$, while a much higher significance level was attained (figure 2).

Significant negative correlations were found between ALA-D and $\varepsilon^{\prime \prime}$ and $\varepsilon^{\prime}$ at low shear rates (table 3).

Table 1 shows that no significant differences existed between the exposed and unexposed groups for total cholesterol, the high-density and low-density lipoprotein fraction, triglycerides, or fibrinogen. Furthermore, no significant correlations were found between these parameters and $\mathrm{B}-\mathrm{Pb}$ or ALA-D.

\section{Aggregation and filtration index for the erythrocytes}

As pointed out in the Methods section, it is possible to calculate the aggregation (AI), and filtration index (FI)

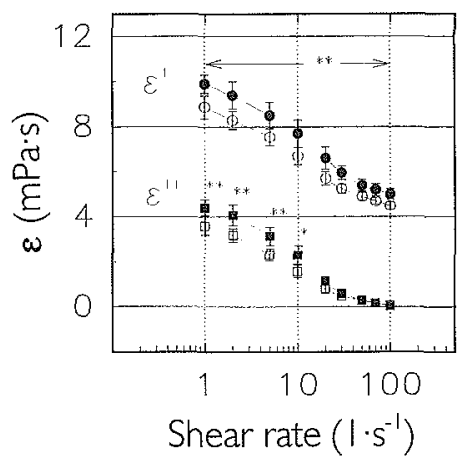

Figure 1. Mean viscoelastic values at shear rates between $1 \cdot \mathrm{s}^{-1}$ and $100 \cdot s^{-1}$. $\left(\varepsilon^{\prime}=\right.$ viscous component of whole blood viscosity, $\varepsilon^{\prime \prime}=$ elastic component of whole blood viscosity, open symbols = unexposed workers, filled symbols = exposed workers.

for erythrocytes. When the dynamic estimated curves for whole blood viscosity were taken into consideration and equations 1 and 2 were applied for each subject, the mean aggregation $(\mathrm{P}<0.001)$ and mean filtration index $(\mathrm{P}<0.002)$ were significantly elevated for the exposed workers in comparison with that of the unexposed workers (table 2).

\section{Discussion}

Contrary to indirect methods determining erythrocyte fluidity using depolarization fluorescence and electron spin resonance spectroscopy, a direct method determining the viscoelastic properties of whole blood for workers exposed to lead was investigated for the first time. The results show that $\varepsilon^{\prime \prime}$, the elastic component, which characterizes the storage of the elastic energy of erythrocytes, is significantly dose dependent, being elevated only at low shear rates. However $\varepsilon^{\prime}$, the viscous compo-

Table 3. Correlation $r_{s}$ (Spearman rank) and $P$-values for the blood lead and delta-aminolevulinic acid dehydrase concentrations and the $\varepsilon^{\prime}$ and $\varepsilon^{\prime \prime}$ (viscous and elastic components, respectively, of whole blood viscosity) at different shear rates in the lead-exposed group. (NS = not significant)

\begin{tabular}{|c|c|c|c|c|}
\hline \multirow[t]{2}{*}{ Shear rate } & \multicolumn{2}{|c|}{ Blood lead } & \multicolumn{2}{|c|}{$\begin{array}{c}\text { Delta- } \\
\text { aminolevulinic } \\
\text { acid dehydrase }\end{array}$} \\
\hline & $r_{s}$ & P-value & $r_{s}$ & P-value \\
\hline \multicolumn{5}{|l|}{$1 \cdot \mathrm{s}^{-1}$} \\
\hline $\begin{array}{l}\varepsilon^{\prime} \\
\varepsilon^{\prime \prime}\end{array}$ & $\begin{array}{l}0.68 \\
0.68\end{array}$ & $\begin{array}{l}0.01 \\
0.01\end{array}$ & $\begin{array}{l}-0.63 \\
-0.68\end{array}$ & $\begin{array}{l}0.02 \\
0.02\end{array}$ \\
\hline \multicolumn{5}{|l|}{$5 \cdot s^{-1}$} \\
\hline $\begin{array}{l}\varepsilon^{\prime} \\
\varepsilon^{\prime \prime}\end{array}$ & $\begin{array}{l}0.63 \\
0.76\end{array}$ & $\begin{array}{l}0.02 \\
0.006\end{array}$ & $\begin{array}{l}-0.69 \\
-0.70\end{array}$ & $\begin{array}{l}0.01 \\
0.02\end{array}$ \\
\hline \multicolumn{5}{|l|}{$50 \cdot \mathrm{S}^{-1}$} \\
\hline $\begin{array}{l}\varepsilon^{\prime} \\
\varepsilon^{\prime \prime}\end{array}$ & $\begin{array}{l}0.63 \\
0.4\end{array}$ & $\begin{array}{r}0.02 \\
\text { NS }\end{array}$ & $\begin{array}{l}-0.60 \\
-0.51\end{array}$ & $\begin{array}{c}0.03 \\
\text { NS }\end{array}$ \\
\hline
\end{tabular}

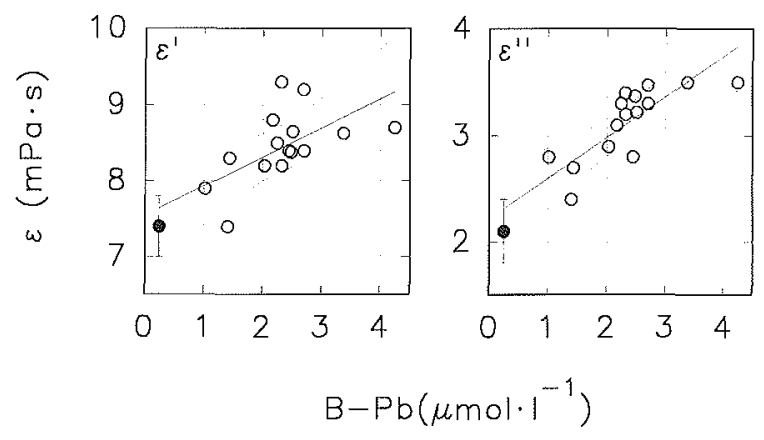

Figure 2. Dose-response relation between blood lead ( $\mathrm{B}-\mathrm{Pb})$ and $\varepsilon^{\prime}$ and $\mathrm{B}-\mathrm{Pb}$ and $\varepsilon^{\prime \prime}$ for the lead-exposed (open symbols) and lead-unexposed workers (filled circles: mean and SD) at a shear rate of $5 \cdot \mathrm{S}^{-1}$. (figure on left: $r_{s}=0.65, P=0.009$; figure on right: $r_{s}=0.79, P<0.005$; curved lines $=95 \%$ confidence interval, $\varepsilon^{\prime}=$ viscous component of whole blood viscosity, $\varepsilon^{\prime \prime}=$ elastic component of whole blood viscosity) 
nent of whole blood viscosity, increased throughout the investigated shear rates between $1 \cdot \mathrm{s}^{-1}$ and $100 \cdot \mathrm{s}^{-1}$. Although not enough data were available for higher $\mathrm{B}-\mathrm{Pb}$ concentrations, it seems that this dependency is more likely sigmoidal than linear (figure 3). Qualitatively, these viscoelastic curves imply erythrocytes showing an enhanced rigidity $(18-20)$. Biochemical investigations have demonstrated that erythrocyte cholesterol is increased in lead-exposed workers (11) and that the fluidity of the cholesterol-enriched erythrocytes is decreased (21). Moreover, in vitro experiments have shown that the membrane viscosity of erythrocytes is increased after incubation of ghost membranes for erythrocytes with lead for 1 h (22). Recent electrophysiological studies have shown that lead (active from the inside of the erythrocytes) can mimic $\mathrm{Ca}^{2+}$ ions and activate calcium-dependent potassium channels in erythrocytes even at low concentrations $(23-25)$. The enhanced potassium efflux and additional water transport influence the stability and rheological properties of erythrocytes (23) and result in cell shrinkage. In addition impaired cellular deformability is an important determinant of erythrocyte lifespan in vivo (26) and seems to be one contributing factor for anemia in patients with high B-Pb concentrations (1). Thus our results support these findings.

Although EDTA, used for the anticoagulation of blood samples, may influence both the rigidity of erythrocytes and the $\mathrm{Ca}^{2+}$ shift, the principal modulation of viscoelastic components in lead exposure still seems valid because identical EDTA concentrations were used for the samples from the lead-exposed and lead-unexposed workers. For clarifying this point, comparisons with different anticoagulants like heparin or hirudin should be investigated.

As lead decreases erythrocyte-bound ALA-D activity, the negative correlation between ALA-D and the components of whole blood viscosity is not surprising, but the enzymatic reduction may in turn contribute to a decreased flexibility of erythrocytes.

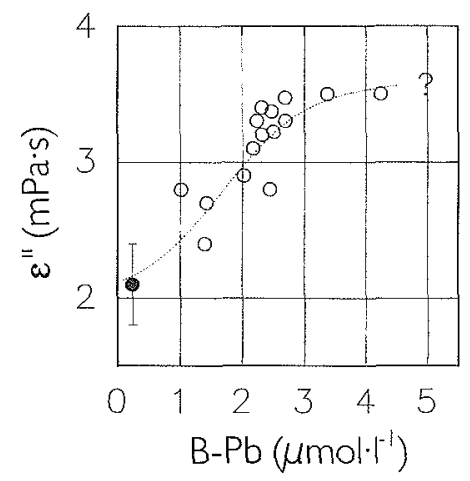

Figure 3. Sigmoidal curve fit between blood lead (B-Pb) and $\varepsilon^{\prime \prime}$ for the lead exposed \& unexposed workers at a shear rate of $5 \cdot S^{-1}$ (broken line). (Filled circle $=$ mean value $\pm \mathrm{SD}$ of the $\mathrm{B}-\mathrm{Pb}$ concentration of the unexposed workers, $\varepsilon^{\prime \prime}=$ elastic component of whole blood viscosity)
With the assumption that, at higher shear rates, aggregates of erythrocytes disrupt and the dissipation of energy is dominated by elongation and orientation, an aggregation and a filtration index for erythrocytes can be calculated (mentioned in the Methods section). Both parameters are significantly increased. In terms of flexibility, this finding is in agreement with that of Chabanel et al (21) and was also found in rats experimentally exposed to lead (27). Concerning increased aggregation, no data are available. However, it seems that the first site of lead fixation is the outer erythrocyte membrane. The lead particles are probably aggregated on the cell surface as a particulate from the lead phosphate $(1,28)$, which may enhance the aggregation tendency of the erythrocytes.

Increased blood viscosity is known to be an independent risk factor for cerebral or cardiovascular diseases and has been recognized in hypertension and renal diseases (29). For lead exposure, conflicting epidemiologic, clinical, and experimental studies exist concerning atherogenesis and impaired cholesterol metabolism ( 30 33). From our data no differences in plasma cholesterol, the high-density or low-density lipoprotein fraction, or triglycerides were seen for the lead-exposed workers, and no lead dose-dependency was found with these parameters. Individual life-style and nutritional habits may mask experimental findings. At least in rats small doses of lead induced an impaired lipid metabolism in rats (34).

In conclusion, the data may contribute to the understanding of the increased risk of lead-exposed persons from the hemorheological point of view. The investigated group was young and healthy, and elevated whole blood viscosity that was lead dependent should not have acted as a harmful risk for them, especially not at a B-Pb of $<1.93 \mu \mathrm{mol} \cdot 1^{-1}$. However, combined with advanced age and atherosclerotic and metabolic diseases (eg, overweight, impaired lipid metabolism, diabetes, etc) the lead-dependent increase in blood viscosity and the aggregation of erythrocytes may contribute to impaired hemorheology and predispose these subjects to microvascular occlusion.

\section{Acknowledgments}

The author would like to thank Ms J Jäger for her excellent and skillful assistance in measuring the lead concentrations in blood and urine.

\section{References}

1. Zenz C. Lead and its compounds. In: Occupational medicine, principles and practical applications. 2nd ed. Chicago, Lon- 
don, Boca Raton (FL): Year Book Medical Publishers Inc, 1988:547-82.

2. Griggs RC. Lead poisoning: hematologic aspect. Prog Hematol 1964:4:117-37.

3. Rubino GF, Prano V, Fiorina L. L'anemia da piombo: sua nature e patogenesi. Folia Med [Napoli] 1959:42:1— 20.

4. Waldron HA. The anemia of lead poisoning: a review. Br J Ind Med 1966;23:83-100.

5. Hasan J, Hernberg S. Interactions of inorganic lead with human red blood cells. Work Environ Health 1966;2:26-32.

6. Fukumoto k, Karai I, Horiguchi S. Effect of lead on erythrocyte membranes. Br J Ind Med 1983;40:220—3.

7. Cook LR, Stohs SJ, Angle CR, Hickman TI, Maxell RC. Erythrocyte membrane microviscosity and phospholipid composition in lead workers. Br J Ind Med 1987;44(12):841 4.

8. Quinlan GJ, Halliwell B, Moorhouse CP, Gutteridge JM. Action of lead(II) and aluminium(III) on iron-stimulated lipid peroxidation in liposomes, erythrocytes and rat liver microsomal fractions. Biochim Biophys Acta 1988;962:166-200.

9. Cocco PL, Cocco E, Anni MS, Flore C, Melis A, Salis S Occupational exposure to lead and blood cholesterol in glucose-6-phosphate dehydrogenase deficient and normal subjects. Res Commun Chem Pathol Pharmacol 1991;72:81—95.

10. Ito $Y$, Niiya $Y$, Kurita H, Shima S, Sarai S. Serum lipid peroxide level and blood superoixde dismutase activity in workers with occupational exposure to lead. Int Arch Occup Environ Health 1985;56:119-27.

11. Valentino M, Fiorini RM, Curatola G, Governa M. Changes of membrane fluidity in erythrocytes of lead-exposed workers. Int Arch Occup Environ Health 1982;51:105-12.

12. Tong P, Thomas T, Wilkinson R. Membrane fluidity is different between intact erythrocytes and ghosts. Biochem Med Metab Biol 1994;52:132-35.

13. Thurston GB. Viscoelasticity of human blood. Biophys J 1972;12:1205-17.

14. Chmiel H, Anadere I, Walitza E. The determination of blood viscoelasticity in clinical hemorheology. Biorheology 1990; $27: 883-94$.

15. Chien S, King RG, Skalak R, Usami S, Copley AL. Viscoelastic properties of human blood and red cell suspension. Biorheology 1975; 12:341-46.

16. Bonsignore D, Calissano P, Cartasegna C. Un semplice metode per la determinazione della $\delta$-aminolevulinico deidratase nel sangue. Med Lav 1965;56:199—206.

17. Haas T, Mache W, Schaller KH, Mache K, Klavis G, Stumpf R. Zur Bestimmung der $\delta$-Aminolävulinsäure-Dehydratase und ihrer diagnostischen Wertigkeit. Int Arch Arbeitsmed 1972;30:87-96.

18. Ribitsch V. Bestimmung der rheologischen Eigenschaften von Erythrozytensuspensionen mittels oszillierender Kapillarströmung. In: Chmiel H, editor. Dynamisch rheologische Messungen in der Klinik. Stuttgart: Vorträge zum Mikrosymposium im Frauenhofer-Institut für Grenzflächen- und Bioverfahrens- techuik, 1987:17-24.

19. Rakow AL, Hochmuth RM. Effect of heat treatment on the elasticity of human erythrocyte membrane. Biophys J 1975; 15:1095-100.

20. Schneditz D, Ribitsch V, Kenner T. Rheological discrimination between native, rigid and aggregated red blood cells in oscillatory flow. Biorheology 1985;22:209-19.

21. Chabanel A, Flamm M, Sung KL, Lee MM, Schachter D, Chien S. Influence of cholesterol content on red cell membrane viscoelasticity and fluidity. Biophys J 1983;44:171—6.

22. Amoruso MA, Witz G, Goldstein BD. Alterations of erythrocyte membrane fluidity by heavy metal cations. Toxicol Ind Health 1987:3:135-44.

23. Erikson LEG, Beving H. Calcium- and lead-activated morphological changes in human erythrocytes: a spin label study of the cytoplasma. Arch Biochem Biophys 1993;303(2):296301.

24. Shields M, Grygorczyk R, Fuhrmann GF, Schwarz W, Passow $\mathrm{H}$. Lead-induced activation of potassium-selective channels in the human red blood cell. Biochim Biophys Acta 1985;815: $223-32$.

25. Leinders T, Van Kleef RGDM, Vijverberg HPM. Distinct metal ion binding sites on $\mathrm{Ca}^{2+}$-activated $\mathrm{K}^{+}$channels in inside-out patches of human erythrocytes. Biochim Biophys Acta 1992;1112:75-82.

26. Weed RI. The importance of erythrocyte deformability. Am J Med 1970;49:147-50.

27. Terayama K. Effects of lead on electrophoretic mobility, membrane sialic acid, deformability and survival of rat erythrocytes. Ind Health 1993;31:113 - 26.

28. Clarkson TW, Kench JE. Uptake of lead by human erythrocytes in vitro. Biochem J 1958;69:432.

29. Dormandy JA. Cardiovascular diseases. In: Chien S, Dormandy J, Ernst E, Matrai A, editors. Clinical hemorheology. Dordrecht, Boston, Lancaster: Martinus Nijhoff Publishers, 1987: 165-94.

30. Michaels D, Zoloth SR, Stern FR. Does low-level lead exposure increase risk of death? A mortality study of newspaper printers. Int J Epidemiol 1991;20:978 - 83.

31. Kristensen TS. Cardiovascular diseases and the work environment: a critical review of the epidemiologic literature on chemical factors. Scand J Work Environ Health 1989;15:245-64.

33. Volpe RA. Re: "Cardiovascular diseases and the work environment: a critical review of the epidemiologic literature on chemical factors" by TS Kristensen. Scand J Work Environ Health 1990;16:147.

34. Malcolm D, Barnet HAR. A mortality study of lead workers 1925-1976. Br J Ind Med 1982;39:404-10.

35. Skoczynska A, Somlik R, Jelen M. Lipid abnormalities in rats given small doses of lead. Arch Toxicol 1993;67:200-4.

Received for publication: 4 December 1995 